\title{
Evaluating Challenges and Competence for Employees in a Chain Providing Corrective Actions to Customers with Mobile Terminals
}

\author{
Andi Mwegerano \\ Nokia Corporation, P.0 Box 86, Fin-24101 Salo \\ andi.mwegerano@nokia.com \\ Tero Ollikainen \\ Nokia Corporation, P.0 Box 86, Fin-24101 Salo
}

\begin{abstract}
This article investigates challenges that are encountered by employees working in a chain that handles customer issues in mobile phones. For a firm to get a competitive advantage over competitors, customer issues should be handled timely and efficiently. To achieve this goal, the employee working in the chain, among other things, must have adequate competence, education and knowledge. This work attempts, through the use of a survey questionnaire, to analyze competences and challenges that are encountered by the employees working in the chain that resolves customer issues. Ordinal logistic regression and item analysis are used for the analysis in this article. The analysis results show that there is a statistical difference in competences in difference service levels within the service chain. The result of this work clearly affects management since it requires that they implement regular training of the products they are handling for all levels in the different stages of the service chain.
\end{abstract}

Keywords: competence, customers, satisfaction, ordinal logistic regression, item analysis.

\section{INTRODUCTION}

The term "competency" refers to a combination of skills, attributes and behaviors that are directly related to successful performance on the job. Core competencies are the skills, attributes and behaviors which are considered important for all staff of the Organization, regardless of their function or level.

Managerial competencies are the skills, attributes and behaviors which are considered essential for staff with managerial or supervisory responsibilities. Taking care that the core competencies are in place ensures that the right employee with right skills is performing the right job with the right output [1]. Core and managerial competencies are not specific to any occupation. One could demonstrate the competency of "teamwork" or "client orientation", for example, in performing any job. Defining competencies is important both for the Organization and for the staff. Competencies are forward-looking. They describe the skills and attributes staff and managers will need in order to build a new organizational culture and meet future challenges. They help organizations clarify expectations, define future development needs, and do more focused recruitment and development planning.

Competencies provide a sound basis for consistent and objective performance standards by creating shared language about what is needed and expected in an Organization. Organizational learning and the ability to create new knowledge are important factors in achieving a sustainable competitive advantage [2]. It is important that the environment for 
learning and knowledge creation is analyzed in order to direct development efforts to the right areas [2].

Much is found in the literature about education and building competences for employees whether it be in a product manufacturing company or in a service firm, however there is few, if any, study cases in mobile terminals in after-sales employee challenges and competences when handling and managing customer issues. Hence this work attempts to fill this gap through a case study. The work investigates challenges that are encountered by employees working in a chain handling customer issues in mobile phones. For a firm to get a competitive advantage over competitors, customer issues should be handled timely and efficiently. To achieve this goal, the employee working in the chain, among other things, must have adequate competence, education and knowledge. This work attempts, through the use of a survey questionnaire, to analyze competences and challenges that are encountered by the employees working in the chain that resolves customer issues. The work is organized in the following manner: Chapter 2 goes through the literature; chapter 3 discusses the data collection and customer issues process; section 4 briefly explains the methods used in this work; section 5 displays the calculated results and discussion; section 5.1 discusses comments from different service levels in the chain; and section 6 concludes the work. Literature and 2 appendixes are finally displayed at the end.

\section{LITERATURE BACKGROUND}

The theory of performance is the foundation for the perception of competency [3]. A researcher [3] assessed through his fundamental contingency theory illustrated in Figure 1 below that maximum performance occurs when person capability or talent is consistent with the requirement of the job needs and structural atmosphere. The person's talent is portrayed by his or her: value, vision, personal viewpoint, knowledge, competences, life and career stage, interest and style [3]. Job requirement can be explained by the role of responsibilities and tasks needed to be done. Attributes of the organizational atmosphere that are anticipated to have a vital impact on the demonstration of competencies and / or the design of the jobs and roles include: culture and climate, structure and systems, maturity of the industry and strategic positioning within it, and attributes of the economic, political, social, environmental, and religious background surrounding the organization.

Figure 1 illustrates the theory of action and job accomplishment: best match implies that maximum performance, stimulation and commitment occurs when there is maximum overlap or integration [3].

Some researchers insist that organizations develop their human resources and enforce the amount of information and knowledge existing in order to distinguish themselves from other organizations [5]. Employees and know-how are highly variable assets for companies [6]. It is vital that the employee's competence and knowledge is continuously assessed and developed [2]. However, researchers argue that the traditional approaches to management, training and development will not provide the learning atmosphere demanded for knowledge tasks [7]. Another researcher argues that individual leaning doesn't guarantee organizational leaning but also asserts that without individual leaning no learning for the firm happens. Hence it is important that that organization supports and services individual learning and knowledge creation [8].

With the help of feedback systems, like surveys, diverse feedback is scientifically collected. The feedback provides an opportunity to gain new knowledge which in turn enables one to have a new vision, goals and strategy [9]. 


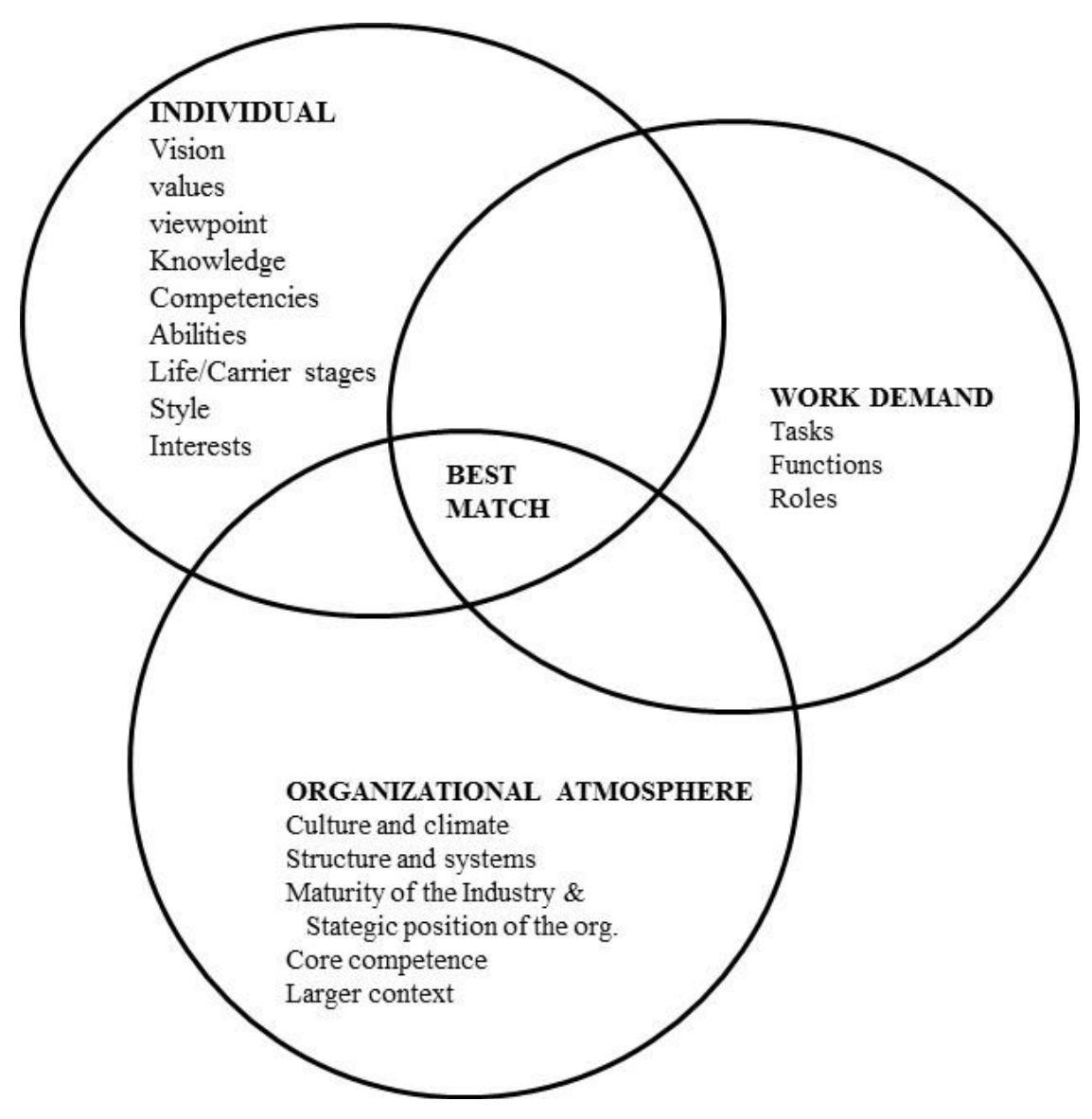

Figure 1. Theory of action and work execution [adapted: 3]

According to 2000 studies about competences done by [10] and his co-workers, the 20 most common competences were identified as shown in Table 2 below together with their associated rating scales, and respective clusters according to the competence dictionary [11].

Table 1:The 20 most common competencies [11]

\begin{tabular}{ll}
\hline $\begin{array}{l}\text { Achievement and action } \\
\text { Achievement orientation } \\
\text { Concern for order, quality and accuracy } \\
\text { Initiative }\end{array}$ & $\begin{array}{l}\text { Helping and human service } \\
\text { Interpersonal understanding } \\
\text { Customer service orientation }\end{array}$ \\
$\begin{array}{l}\text { Information seeking } \\
\text { Impact and influence }\end{array}$ & $\begin{array}{l}\text { Managerial } \\
\text { Developing others }\end{array}$ \\
Impact and influence & Directiveness/assertiveness and \\
Organisational awareness & use of positional power \\
Relationship building & Teamwork and cooperation \\
Cognitive & Team leadership \\
Analytical thinking & Personal effectiveness \\
Conceptual thinking & Self-control \\
Technical/professional/ & Self-confidence \\
managerial expertise & Flexibility \\
\hline
\end{tabular}


Formal competence is measured, for example, by the number of years of schooling completed or by credentials received by an individual [12]. Actual competence is the ability to successfully handle a certain situation or to complete a certain task. In managing a customer's issues, competence as a requirement is needed in order to accomplish assignments effectively and timely, as illustrated in the Figure 2 below

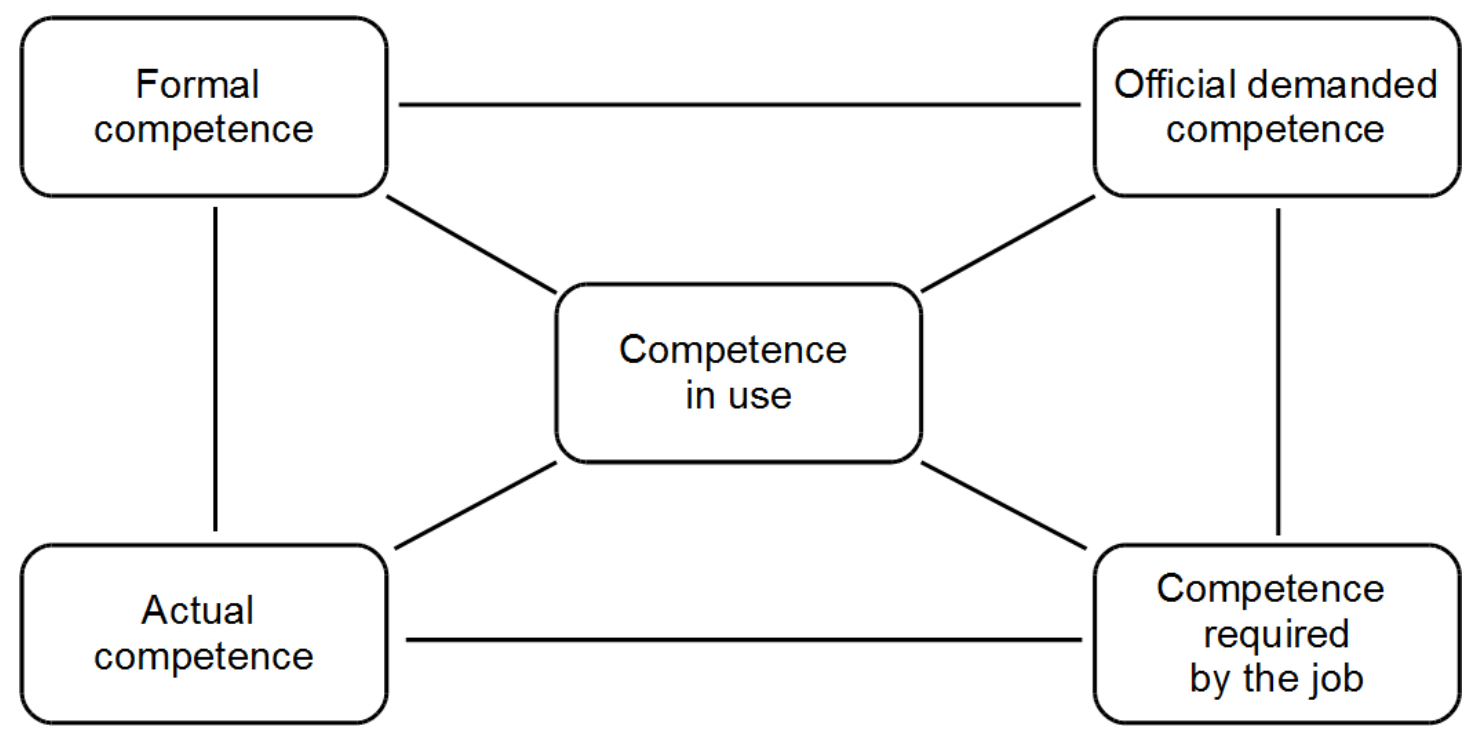

Figure 2: Different meaning of occupational competence [adapted: 12]

\section{ISSUE ESCALATION PROCESS AND DATA COLLECTION}

A web questionnaire was sent to 75 internal employees of Nokia working in a service chain (see Figure 1) allocated in 30 different countries in the world in year 2012. The target respondents L2, L3 and L4 resolves customer issues of mobile terminals raised through an inhouse built tool called GENIUS. The survey consists of 9 background information and 16 questions (15 closed and 1 open). The response rate among the levels (L2, L3 and L4) were distributed as follows in Table 2

Table 2: Response rate by Levels

\begin{tabular}{cc}
\hline Level & Response \% \\
\hline L2 & 36.00 \\
L3 & 26.67 \\
L4 & 33.33 \\
\hline
\end{tabular}

In the business group (BG) most responses came from the following groups tabulated in Table 2

Table 3: Response rate by BG

\begin{tabular}{lc}
\hline BG & Response \% \\
\hline BG1 & 21.33 \\
BG2 & 18.67 \\
BG9 & 21.33 \\
BG10 & 24.00 \\
BG [The rest] & 6.67 \\
\hline
\end{tabular}

Although the questionnaire contains 16 questions only 10 questions (see Appendix I and II) were used in this article. The rest of the questions were used for other purposes of the inhouse development. 


\section{Issue Escalation Process}

Figure 3 illustrates the chain network process for customer issues escalation. For example when a customer $\mathrm{X}$ confronts an issue $\mathrm{Y}$, e.g. ringing tone of the terminal is not functioning well, he/she will contact any authorized service vendor (ASV) i.e. L1 for resolving the issue. If L1 is not able to resolve the issues, it will be escalated to a higher level of service, in this case L2. The procedure will continue in the network chain until a corrective action(s) is provided to the customer (Mwegerano, et. al. 2012)

The process from which data was collected is displayed in Figure 2 below. Respondents were from L2, L3 and L4.

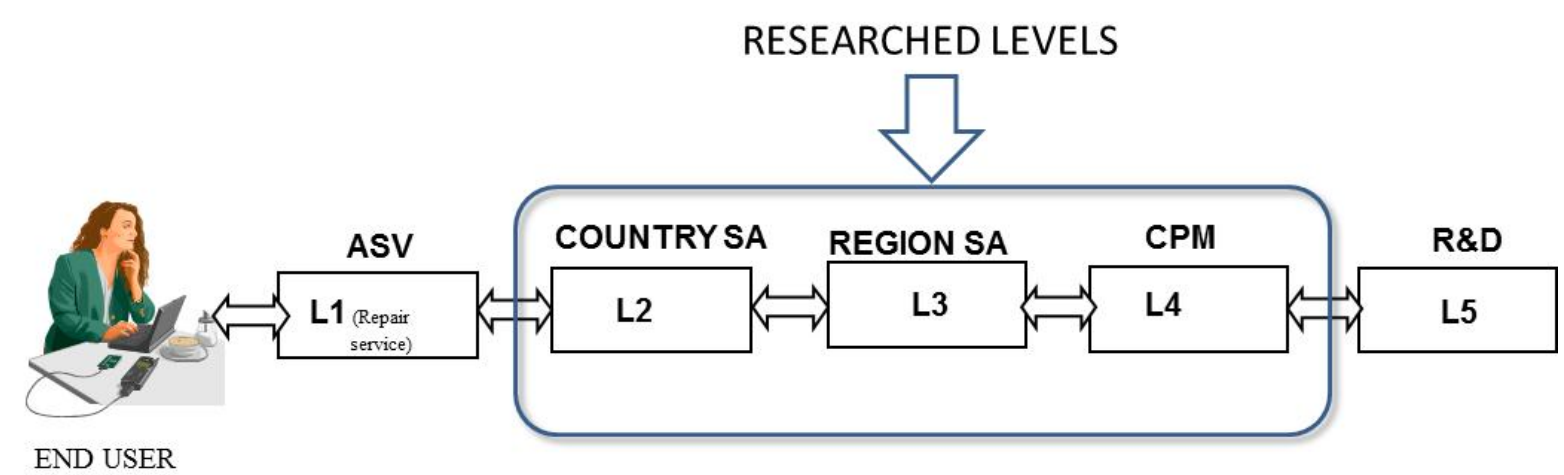

CUSTOMER

L1 = Authorized Service Vendor

L2 = Country Sales Area

L3 = Region Sales Area

L4 $=$ Care Project Manager

L5 $=$ Research and Development

Figure3: A simplified issues escalation path diagram

\section{METHODS}

In this paper, item analysis was used to assess how reliable multiple items in this survey measure the same construct. Questions in further analysis were selected based on internal consistency for all included items.

Furthermore, Cronbach's Alpha for a selected question was calculated. Generic sample distribution comparison per question was done by using Boxplot. Ordinal logistic regression is used to perform logistic regression on a question results. Mood's Median test was carried out to find out whether there was significance in the question results. All the calculations and Figure results were obtained by using a Min Tab statistical tool.

\section{RESULTS AND DISCUSSION}

Questions for further analysis were selected based on internal consistency for all included items. The inter-item correlation matrix displays the strength of the relationship between every pair of items is displayed in Figure 4 below. 


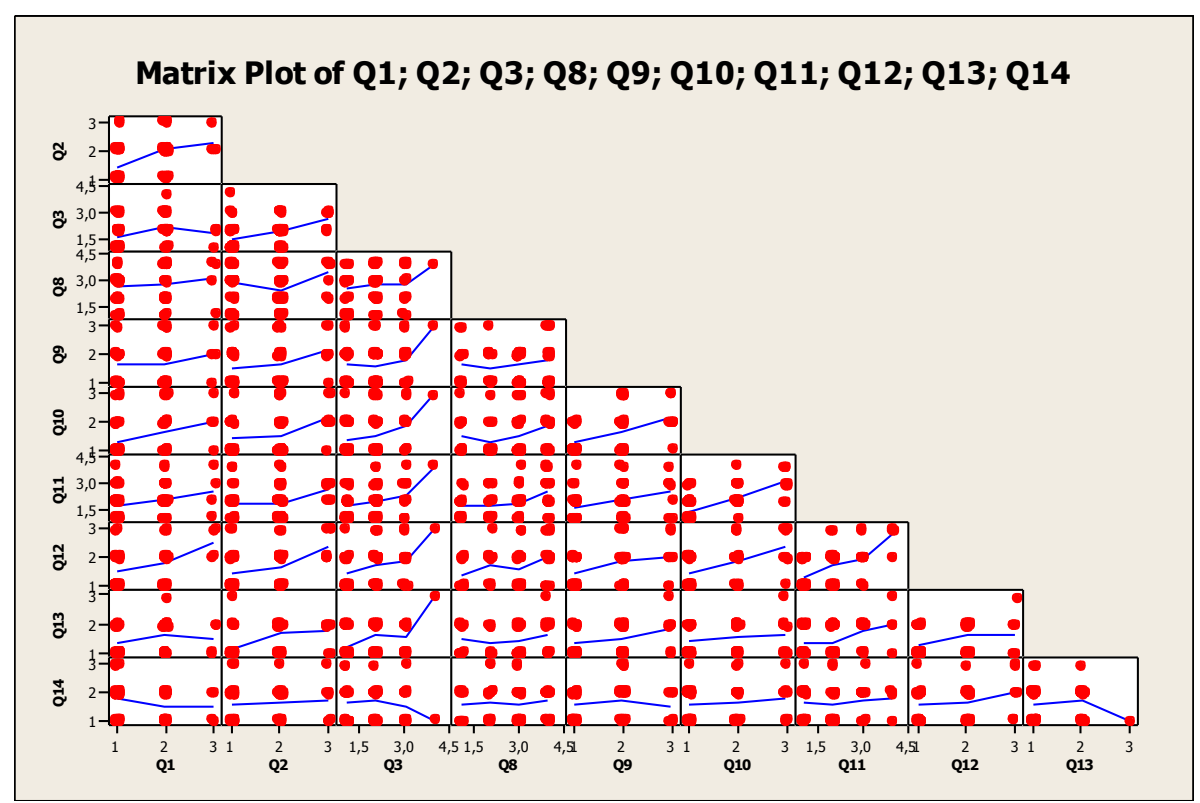

Figure 4: Inter-item correlation matrix

Cronbach's Alpha for selected question is 0.7460 , which is higher than a commonly used benchmark value of 0.7 . This suggests that at least some of the items measure the same construct.

Generic sample distribution comparison per question was done by using Boxplot -chart displayed in Figure 5

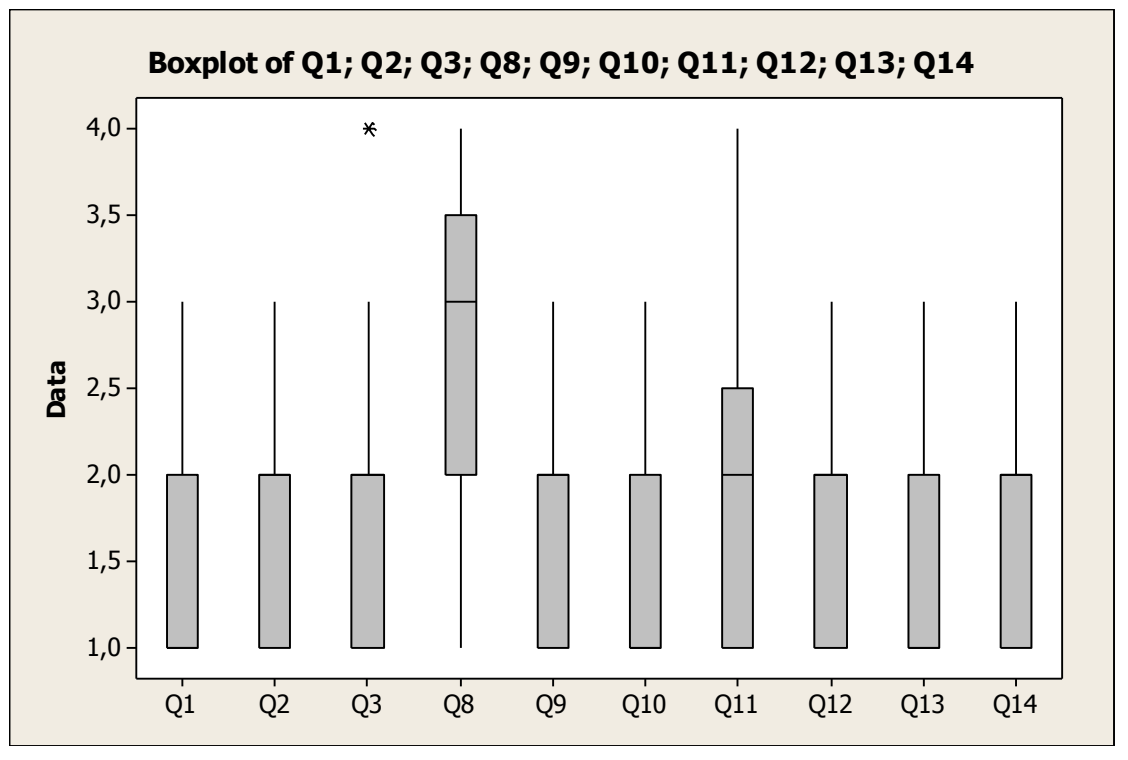

\begin{tabular}{cc}
\hline Question & Median \\
\hline Q1 & 1 \\
Q2 & 2 \\
Q3 & 2 \\
Q8 & 3 \\
Q9 & 2 \\
Q10 & 1 \\
Q11 & 2 \\
Q12 & 2 \\
Q13 & 1 \\
Q14 & 2 \\
Total & 2
\end{tabular}

Figure 5: Box plot of the questioners results (Q1-Q3, Q8-Q14)

In general the questionnaire results are quite good, with medians ranging from 1 to 3 from question to question having total Median of 2 (In Likert -scale Often and Partially) as shown in Table 4.

Predictors used in regression analysis are Level (Question 1.2), Nokia employment time (Question 1.7) and Cap Genius usage time (Question 1.8)

Mood's Median test shows that there is statistically significant $(\mathrm{P}=0.000)$ difference between 
Mwegerano, A., Ollikainen, T., (2014). Evaluating Challenges and Competence for Employees in a Chain Providing Corrective Actions to Customers with Mobile Terminals. Archives of Business Research, 2(1), 10-22

question results. Results from Question 8 "Do you have regular trainings on different products you are handling in cap genius tool?" suggest that more emphasis for product trainings is in place (Median 3 "Sometimes").

Table 4: Mood Median Test: Results versus Questions

\begin{tabular}{|c|c|c|c|c|c|}
\hline & & & & & Individual $95,0 \% \mathrm{CI}$ s \\
\hline Question & $\mathrm{N}<$ & $\mathrm{N}>=$ & Median & Q3-Q1 & 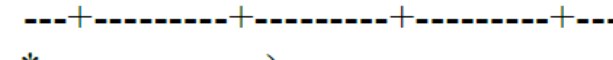 \\
\hline Q1 & 38 & 37 & 1,00 & 1,00 & *---------------) \\
\hline Q10 & 39 & 36 & 1,00 & 1,00 & *----------------) \\
\hline Q11 & 26 & 49 & 2,00 & 2,00 & $*$ \\
\hline Q12 & 32 & 42 & 2,00 & 1,00 & 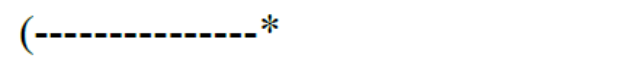 \\
\hline Q13 & 39 & 36 & 1,00 & 1,00 & *----------------) \\
\hline Q14 & 32 & 43 & 2,00 & 1,00 & (------------.* \\
\hline Q2 & 31 & 43 & 2,00 & 1,00 & (---------------* \\
\hline Q3 & 26 & 48 & 2,00 & 1,00 & $*$ \\
\hline Q8 & 13 & 62 & 3,00 & 2,00 & $(-----*$ \\
\hline \multirow[t]{3}{*}{ Q9 } & 32 & 42 & 2,00 & 1,00 & (--------------* \\
\hline & & & & & ---+---------+---------+---------+--- \\
\hline & & & & & 2,40 \\
\hline
\end{tabular}

Overall median $=2,00$

Table 5: Goodness-of-fit

\begin{tabular}{cc} 
Question & Pearson P-Value \\
\hline Q1 & 0,006 \\
Q2 & 0,273 \\
Q3 & 0,385 \\
Q8 & 0,208 \\
Q9 & 0,123 \\
Q10 & 0,394 \\
Q11 & 0,526 \\
Q12 & 0,282 \\
Q13 & 0,771 \\
Q14 & 0,150
\end{tabular}

Table 5 above displays the summary of the logistic regression analysis of Good-of -fit with Pearson values for the selected questions. Pearson P-value indicates how well the model fits your data. 
Table 6: Logistic Regression of Q1

\begin{tabular}{|c|c|c|c|c|c|c|c|}
\hline \multirow[b]{2}{*}{ Predictor } & \multirow[b]{2}{*}{ Coef. } & \multirow[b]{2}{*}{ SE coef. } & \multirow[b]{2}{*}{ z } & \multirow[b]{2}{*}{$\mathrm{p}$} & \multirow{2}{*}{$\begin{array}{l}\text { Odds } \\
\text { Ratio }\end{array}$} & \multicolumn{2}{|c|}{$95 \% \mathrm{CI}$} \\
\hline & & & & & & Lower & Upper \\
\hline Const(1) & 0,673081 & 1,40731 & 0,48 & 0,632 & & & \\
\hline \multirow{2}{*}{\multicolumn{8}{|c|}{$\mathrm{L}$}} \\
\hline & & & & & & & \\
\hline 3 & $-1,10870$ & 0,630670 & $-1,76$ & 0,079 & 0,33 & 0,10 & 1,14 \\
\hline 4 & $-1,73011$ & 0,598580 & $-2,89$ & 0,004 & 0,18 & 0,05 & 0,57 \\
\hline WE 1 trans & $-0,0913703$ & 0,0805913 & $-1,13$ & 0,257 & 0,91 & 0,78 & 1,07 \\
\hline WE 2 trans & 0,541715 & 0,682894 & 0,79 & 0,428 & 1,72 & 0,45 & 6,55 \\
\hline \multicolumn{8}{|c|}{ Log-Likelihood $=-58,411$} \\
\hline \multicolumn{8}{|c|}{ Goodness -of-Fit Tests } \\
\hline Method & Chi-Square & DF & $\mathrm{p}$ & & & & \\
\hline Pearson & 178,196 & 134 & 0,006 & & & & \\
\hline Deviance & 116,821 & 134 & 0,855 & & & & \\
\hline
\end{tabular}

From Table 6 it can be seen that there is a statistical significance between levels in Question 1

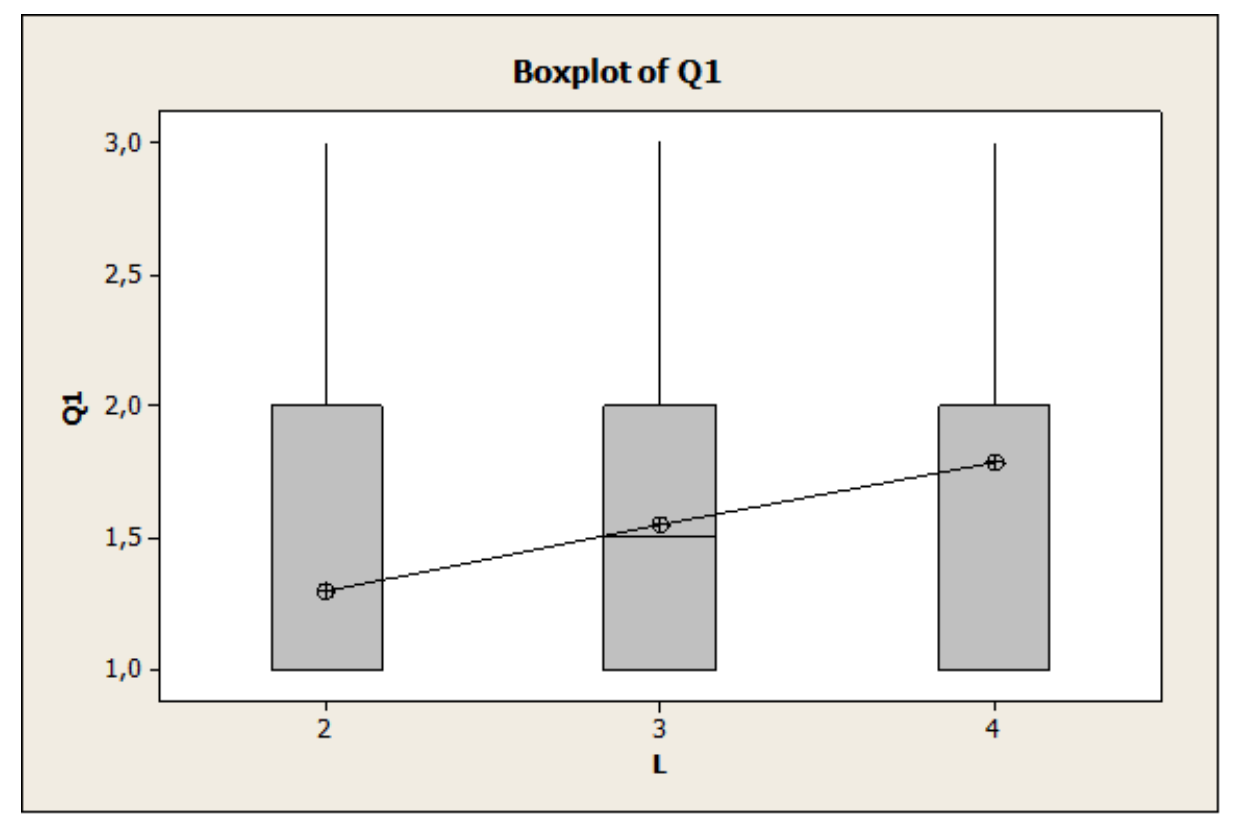

Figure 6: The Boxplot of service level's performance

From Figure 6 it can be seen that service level 2 (L2) had ca.1.3 average score performance while service level 4 (L4) had ca.1,75 average score performance. This implies that L2 had the best performance average score.

\section{Open Questions Remarks and Comments from the Respondents (L2-L4)}

From the service level 4 (L4) point of view, it was noted that the lower levels, in this case L2 and L3, do not seem to provide immediately enough information about the issue to the 
resolvers, normally L4. Lower service levels should filter more issues by reading product manuals and specifications to reduce unnecessary issue escalation to higher levels and hence reducing the issue resolution times for the customers. The business impact of an issue should always, if possible, be attached when escalating it to higher levels. The business impact will give the resolvers an opportunity to prioritize those issues according to the business impact reported from the field. The business impact could include for example, how wide geographically the issue has spread, how great is the number of mobile terminals affected, financial loss incurred already, and a forecast of how much more would the business lose if the issues are not resolved fast and well. Lower levels should be equipped with enough tools to handle and manage their customers. L4 noted that the lower levels should have an understanding of how the resolvers' process functions before corrective actions can be provided to the customers. This could give an understanding why some issues take a long time to be resolved and others not. New product training in this group was non-existent according to some respondents. Issue reporting tools between $\mathrm{L} 4$ and R\&D was reported as inconvenient because the tools are different from the ones used by all other service levels, i.e. from L1-L4. The L4 service group concluded that there should be some key performance indicator (KPI) for every service individual on the service chain (ref. Figure 3)

From the point of view of service level L3, they would like to have more visibility of the issue status on a regular basis. Similar issues with common corrective actions should be identified and sent back for closing to reduce the lead time metrics for the teams. The faulty sample terminals delivery process can jeopardize the issue resolution times due to custom formalities and other paper work needed for sending the samples to the resolvers. Sometimes the provided corrective actions do not match with the root cause of the issue hence issues are experienced through the life of the product. Corrective actions should be improved by the issue resolvers, in this case $\mathrm{L} 4$ and $\mathrm{R} \& \mathrm{D}$.

From the point of view of service level L2, more options should be incorporated into the escalation tool such as a video attachment, so that the issues can be well explained to the resolvers. It causes a lot of pain to fill all the fields in the tool such as adding something in the database when something is accidentally missing or has been wrongly uploaded, before escalating an issue to the resolvers just to find out that it takes a long time to provide corrective actions.

\section{CONCLUSION}

This case study work has examined some challenges found in the service chain handling that handles customer issues with mobile terminals. Also the paper has attempted to analyze some competence gaps among service levels or members. Mood's Median test shows that there is statistically significant $(P=0,00)$ difference between question results. Results from Question 8 (see Table 4) reveals that more regular training for different product is needed (median 3 "sometimes"). This also had been noted in the previous work [13]. This was also echoed in the opening comments. Service level L2 had the best average score (1.3) in performance while service level L4 had the lowest average score i.e., 1.75 (see Fig 6). This paper has a managerial implication for further actions to be taken to examine and implement the required resources or time to see that the service staffs get sufficient product trainings and in time. Further work could be extended to make a longitudinal survey of the total chain from the field L1 to R\&D and also to add more explanatory variables like actual response times given by the issue resolvers to customers and also the quality of correction actions as perceived by customers. 


\section{REFERENCES}

[1] M. Desmukh, and M. Godse, "Muddling Through Competencies at Work", CSI Communication, 31-32 (April 2012)

[2] J. Kantola, Paajanen, P. and H. Vanharanta, "Knowledge Creation and Learning" Systemics, Cybernetics and Informatics 3(3) (2009)

[3] R. E. Boyatzis, “Competencies in the 21st century” Journal of Management Development, 27(1) 5-12 (2008)

[4] R.E. Boyatzis, “The competent Manager: A Model for Effective Performance”, John Wiley \& Sons, New York, NY (1992)

[5] P. Ruotie and J.Honka, “ Osaamisen Kehittäminen Organisaatiossa”, Seinajoki Consulting team, 1997

[6] A. De Geus, “The Living Company, Boston” Harward Business School Press, (1997)

[7] J.W.M. Kessels, "Learning in Organizations: a Corporate Curriculum for the Knowledge Economy," Futures, 33(6) 497- 506 (2001)

[8] P.M. Senge, “The fifth discipline: The art and practice of the learning organization," New York; Doubleday, (1991)

[9] P. Sydänmaanlakka, "Älykäs organisaatio: tiedon, osaamiseen ja suorituksen johtaminen", Helsinki: Kauppakaari Oyj, (2001)

[10] D. McClelland, “Testing for competence rather than intelligence,” American Psychologist, 28 (1), 1-14 (1973)

[11] Spencer and S. Spencer, “Competence at work: A Model for Superior Performance” New York John Wiley, (1993)

[12] P.E. Ellström, “The many meaning of Occupational competence and Qualification,” Journal of Industrial training, 21(6/7), 266-273 (1997)

[13] A. Mwegerano, P. Kytösaho and A. Tuominen, Applying Self-Organizing Maps Method to Analyze Corrective Actions Quality in Mobile Terminals" Journal of iBusiness, 2 (2012)

\section{APPENDIX I:}

\section{Bar Charts Results By Questions}

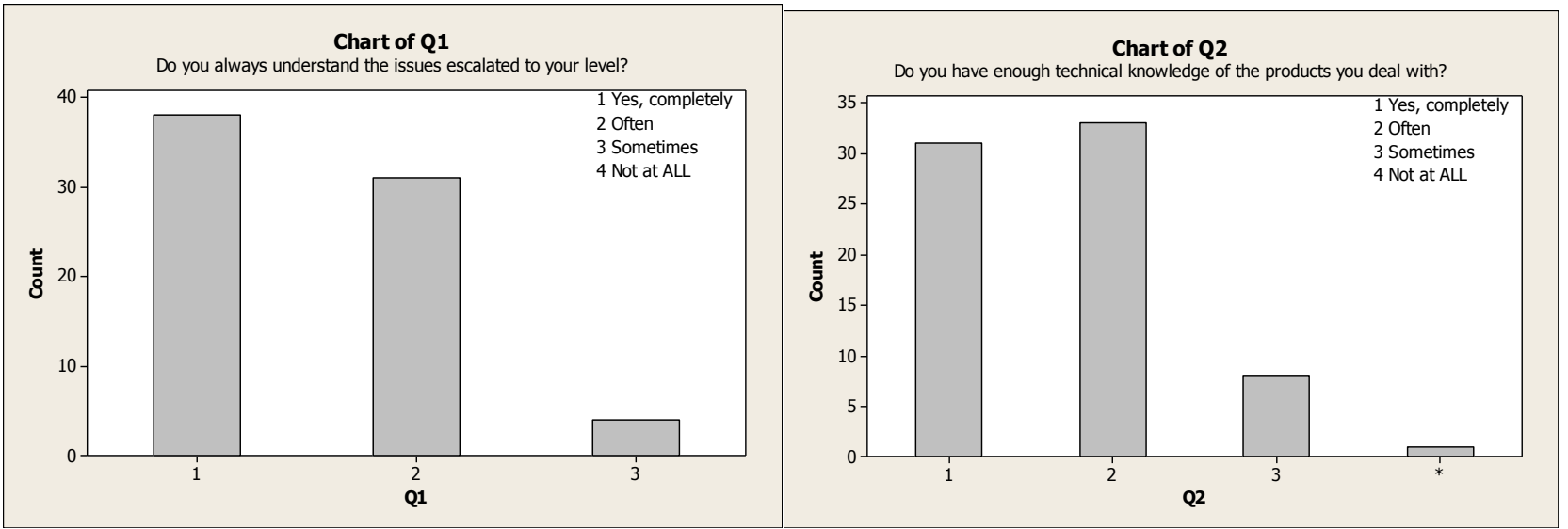


Mwegerano, A., Ollikainen, T., (2014). Evaluating Challenges and Competence for Employees in a Chain Providing Corrective Actions to Customers with Mobile Terminals. Archives of Business Research, 2(1), 10-22

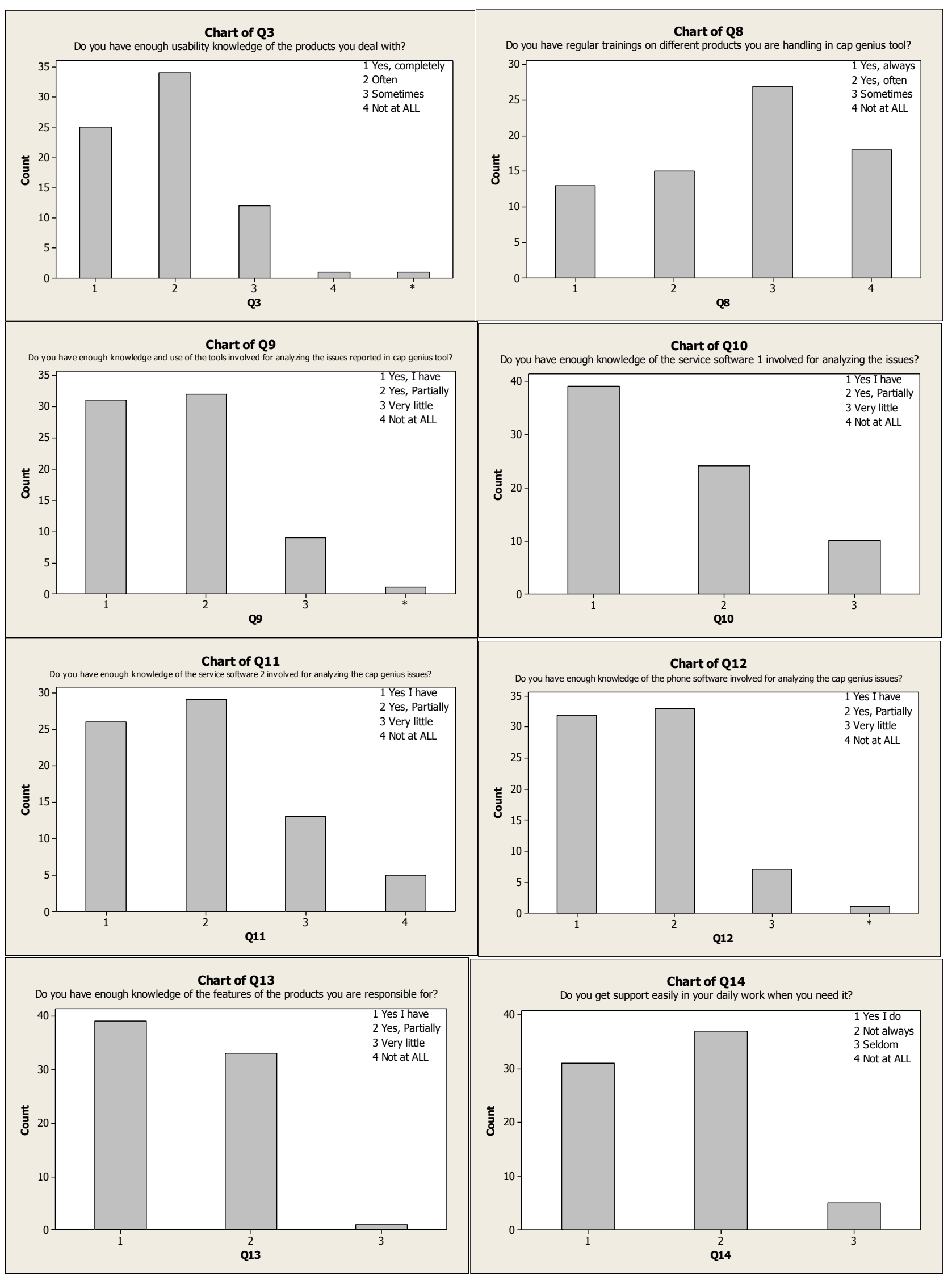




\section{APPENDIX II \\ Challenges In A Chain Working For Corrective Actions In Cap Genius Tool}

It is important for the after-sales managers to know what challenges are being faced, and what is the performance of the employees working in a network channel that handles customer issues in mobile terminals. This study is also an ongoing Licentiate's research thesis. Hence your responses are very important. It would require around 10 minutes to answer. Your response will be kept confidential and only aggregate level and /or responses will be reported to the managers. For any question regarding the survey, please feel free to contact andi.mwegerano at $\}$ nokia.com

\section{BACKGROUND INFORMATION}

1.1 Which of the following best describes your background?

$$
\begin{aligned}
& \text { Technical } \\
& \text { Business } \\
& \text { All above } \\
& \text { Others, please specify: }
\end{aligned}
$$

1.2 At which Genius level do you work?

$$
\begin{array}{ll}
\text { L2 } \\
\text { L3 } \\
\text { L4 }
\end{array}
$$

1.3 In which sales area do you work for? Select...

1.4 In which country are you located?

1.5 How long have you been working for Nokia in overall [Time in months]

1.6 How long have you been handling the CAP GENIUS issues for Nokia [Time in months]

1.7 Business group working with at the moment

\section{QUESTIONNAIRES SURVEY}

1. Do you always understand the issues escalated to your level?

2. Do you have enough technical knowledge of the products you deal with?

3. Do you have enough usability knowledge of the products you deal with?

\begin{tabular}{|l|}
\hline Select... \\
\hline Select...
\end{tabular}

4. Do you have enough time to verify the issues escalated to your level before escalating or transfer them to any of the levels? Select...

5. Do you feel the lower levels are not evaluating the issues enough before they escalate to your level?

6. Do you feel the upper levels are not evaluating the issues enough before they ask for more information from your level? [NB: For L4 the upper level for you is the L5 or the designers in R\&D outside of cap genius tool] Select... $\quad$.

7. Are you confident on using the cap genius tool for handling the reported issues to your level? Select..

8. Do you have regular trainings on different products you are handling in cap genius tool? Select...

9. Do you have enough knowledge and use of the tools involved for analyzing the issues reported in cap genius tool? Select... 
10. Do you have enough knowledge of the service software (Phoenix) involved for analyzing the issues? Select... 11. Do you have enough knowledge of the service software (Nokia Care Suite) involved for analyzing the cap genius issues?

12. Do you have enough knowledge of the phone software involved for analyzing the cap genius issues?

13. Do you have enough knowledge of the phone features of the products you are responsible for?

14. Do you get support easily in your daily work when you need it? Select...

15. How do you prioritize your issues when handling for corrective actions?

Select...

16. Please, enter here any comments regarding competence, improvements or any suggestion regarding your work in the cap genius chain.

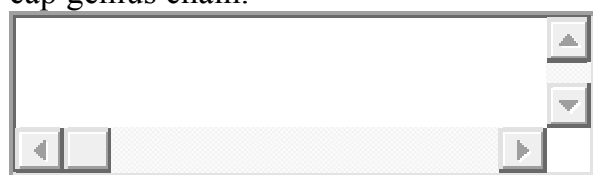

Thank you for taking your time to complete this survey! 